\title{
Quarrel Leading To Death of a 14 Years Old Girl by Multiple Suicidal Attempts- A Rare Case Report
}

\author{
Biswas Sujash $^{1}$, Das Abhishek ${ }^{2}$, Chandan Bandopadhyay ${ }^{3}$, Roy Avijit Roy ${ }^{4}$, \\ Dalal Deepsekhar ${ }^{5}$, Dey Arijit ${ }^{6}$. \\ 1: Demonstrator, Medical College, Kolkata \\ 2: $3 r d$ year PGT, Nil Ratan Sircar Medical College, Kolkata \\ 3: Demonstrator, Medical College, Kolkata \\ 4: 3rd year PGT, Nil Ratan Sircar Medical College, Kolkata \\ 5: 3rd year PGT, Nil Ratan Sircar Medical College, Kolkata \\ 6: $1^{\text {st }}$ year PGT, Nil Ratan Sircar Medical College, Kolkata
}

\begin{abstract}
Suicide is taking away someone's own life. Attempt to commit suicide or commission of suicide is a crime and should be punished as per Sec. 309 of IPC ${ }^{[l]}$. A successful suicidal attempt is that rarest crime where victim and accused is same individual and court becomes helpless to punish the accused. Suicide among teenagers is becoming a major problem day by day. Young boys and girls often choose it as a way to get rid of their sufferings. Such a case when brought to mortuary of NRSMC\&H for post mortem examination, there was no history regarding cause and manner of death. A 14 years old girl was found lying unconscious on her bed in her residence. She was declared brought dead in the emergency ward of hospital. A meticulous post mortem examination revealed that it was a case of suicide with two suicidal attempts (hanging and poisoning). Autopsy focussed the first ray of light to the investigation which was later confirmed by the investigators by chemical examination report and suicide note. Here lies the success of a medicolegal expert in solving mystery of a death.
\end{abstract}

Key Words: Suicide, Hanging, Poisoning, Autopsy

\section{Introduction:}

A death, sudden, suspicious and unnatural, is always a mystery. In solving the mystery, law depends on forensic experts. Many a times the job starts with no history or clue regarding the cause and manner of death but it's their expertise that makes the sterile ground of investigation a fertile one. Various means of suicide are adopted by different age groups of people. Hanging and intake of poison are two very common ways of suicidal attempts. Sometimes one individual adopts multiple means to make the death sure. Sometimes people fail in one attempt and try again with some other method in the same episode. These types of multiple attempts at one time or at different times become difficult to be detected by post mortem examination. Such a happening also reflects the hesitative status of mind of the person.

\section{History:}

It was a homely matter and purely family affair. A 14 years old girl locked herself in a room after a quarrel with her mother. After a while when she did not open the door, the family members knocked the door and still the door was not opened by the girl. There was even no response from the room. Ultimately the door was broken and the girl was found lying on the bed in unconscious state. The girl was immediately taken to the nearest hospital. Medical officer in the emergency ward declared the girl brought dead. With no anticipation about cause of death, the dead body was sent to the mortuary of NRS Medical College and Hospital for post mortem examination. History was obtained from police inquest and family members.

\section{Post Mortem Findings:}

It was much unexpected to observe a round mark of pressure abrasion surrounding the neck. The mark was 9" long and 1" wide. Upper end of the mark was 2.5 " below tip of right mastoid process, 2" bellow right angle of mandible, 1" bellow left angle of mandible and 1" bellow tip of left mastoid process. Lower end of the mark was 4" above suprasternal notch in the midline. The mark was oblique, non-continuous and there was a gap of 4" over posterior aspect of neck starting from a point 1" posterior to tip of left mastoid process and ending at a point 1 " right to midline over posterior aspect of neck. The mark of pressure abrasion was reddish in colour and non scabbed. There was an abrasion measuring 1 "x 0.5 " over left chin 1 " medial to left angle of mandible. This abrasion was brown scabbed which was not consistent with the nature of previously mentioned abrasion. No other external injury was found over body. 


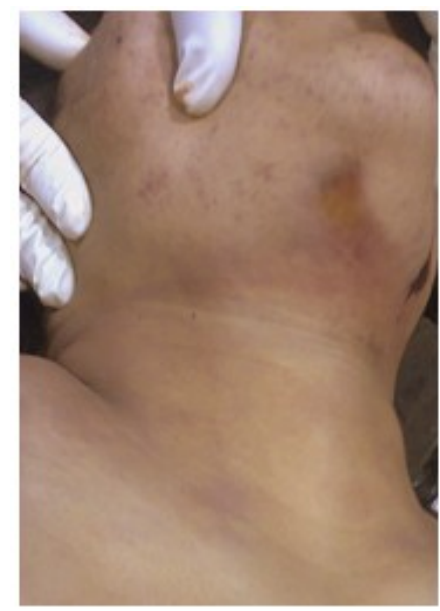

Fig:1-Pressure abrasion over neck

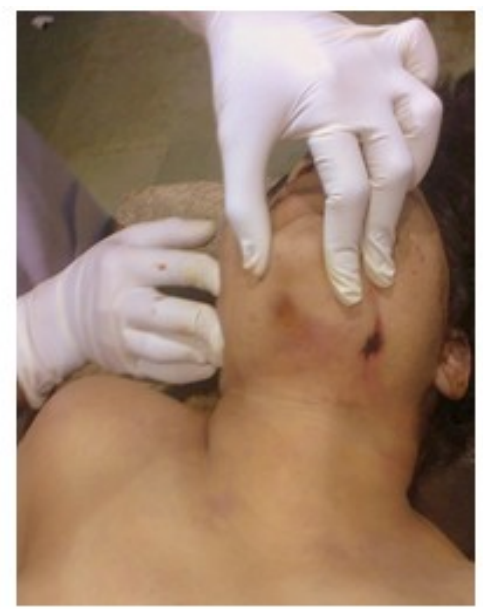

Fig:2-Pressure abrasion over neck and ligature mark

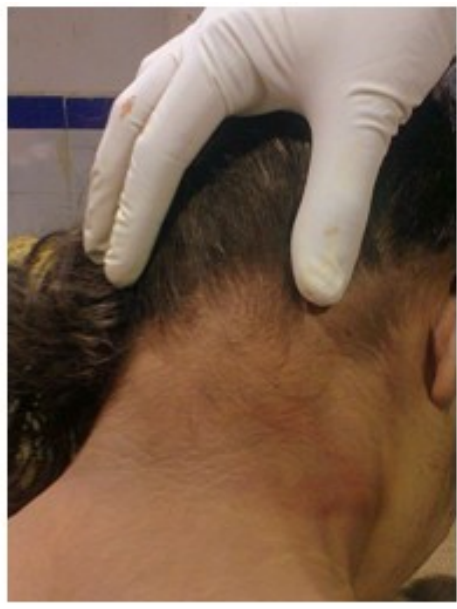

Fig:3- Gap in the ligature mark

Internally all organs were grossly congested. There was about $200 \mathrm{ml}$ yellowish fluid within the stomach. The content of stomach had a peculiar pungent smell like that of a smell of insecticide. Inner wall of stomach showed presence of sub-mucosal haemorrhage. Content of stomach along with 200 gm of liver, proximal part of duodenum and half of each kidney were sent to Forensic Science Laboratory for chemical examination to detect whether there was any poison or not.

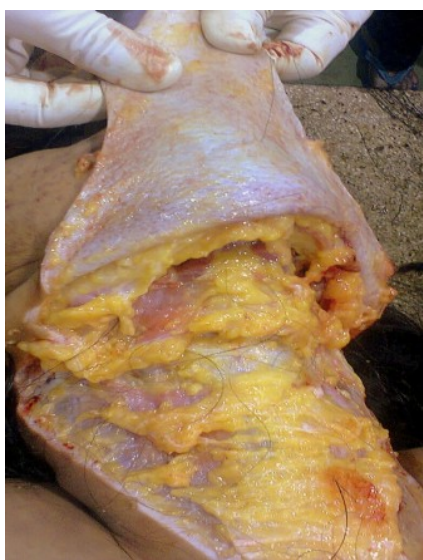

Fig:4- Ligature mark on dissection

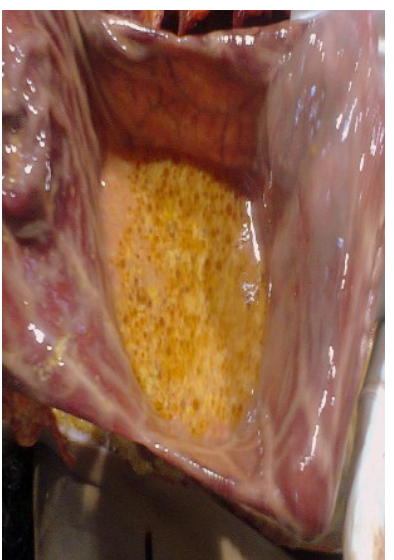

Fig:5-Stomach with content after dissection

\section{Discussion:}

High risk factors include leaving suicide notes, family history of suicide, and history of previous attempt. Almost $95 \%$ of persons who attempt or commit suicide have a diagnosed mental disorder, of which $80 \%$ accounts for depression. ${ }^{[2]}$. Suicide note was there in this case though no previous history of attempt was there. Firearm injury and hanging are active suicidal methods whereas poisoning and drowning are help-seeking methods. Male suicide attempts are more violent ${ }^{[3]}$. So, this case is a rare combination of complex mode of suicide by through multiple means. In 2011 in India, occupational statistics among suicide victims showed highest incidence among self-employed $(38.3 \%)$ persons ${ }^{[4]}$.

\section{Conclusion}

The evaluation and diagnosis of suicidal risk and attempt are the most complex as well as difficult tasks. The surrounding persons \& clinician must always try to find out the suicidal ideation or probability of attempts if a person is depressed or emotionally unstable. No single approach is appropriate for all persons in similar situations as suicide is an outcome of complex interactions of various risk factors and protective mechanisms ${ }^{[5]}$. WHO suggested broad array of its preventive interventions addressing different factors at different levels required to achieve overall reduction in the population suicide rate ${ }^{[6]}$. An overall psychiatric awareness and lifestyle modification is very essential to stop this kind of incidences. 
Conflict Of Interest: This article was not sponsored by anyone and was done exclusively by the authors with their own resource and interest.

Source of Funding: Nil

Ethical Clearance: Not applicable

\section{Reference}

[1]. Reddy KSN. The Essentials of Forensic Medicine and Toxicology, 32nd Ed. K.Saguna Devi, Hyderabad, 2013; p 205-206, 277-278

[2]. Sadock BJ,Sadock VA. Kaplan \& Sadock's Synopsis of Psychiatry:Behavioral Sciences/Clinical Psychiatry, 10th Ed, chapter-

[3]. New Oxford Textbook of Psychiatry, p 951-978

[4]. www.ncrb.nic.in/CD-ADS12011/suicides-11.pdf

[5]. Casey P, Kelly B. Fish's Clinical Psychopathology: Signs and Symptoms in Psychiatry, 3rd Ed. p 65-75

[6]. WHO suicide prevention strategy.pdf (www.euro.who.int/Document/E83583.pdf) 